\title{
Investigations on Dispersion Compensation using Fiber Braggs Grating
}

\author{
Er. Abhishek Sharma \\ M. Tech student (ECE) \\ Eternal University \\ H.P (India)
}

\author{
Er. Sukhbir Singh \\ Assistant Professor (ECE) \\ Eternal University \\ H.P (India)
}

\author{
Er. Bhubneshwar Sharma \\ Assistant Professor (ECE) \\ Eternal University \\ H.P (India)
}

\begin{abstract}
Optical fiber plays a very important role in communication system for data transmission. Optical fiber has many advantages which makes it for better transmission of data. Dispersion is the main factor which affects the performance of fiber. There are various ways which can compensate the fiber dispersion. Dispersion compensation by FBG (fiber bragg grating) is one of them. This paper investigates dispersion compensation of optical communication system by FBGs along with EDFA (erbium doped fiber amplifier). Dispersion compensation is done by FBG along with EDFA before the fiber (at the transmitter end) in the optical transmission system and FBG along with EDFA after the fiber (at the receiver end) in the optical transmission system. Minimum BER is obtained by using FBG along with EDFA before the fiber (at the transmitter end) in the optical transmission system as compare to FBG along with EDFA after the fiber (at the receiver end) in the optical transmission system. For 50 $\mathrm{km}$ BER reduces from $1.10874 \mathrm{e}-102$ (at receiver side) to 4.16583e-181 (transmitter side).
\end{abstract}

\section{General Terms}

Dispersion, Fiber Bragg Grating (FBG), Dispersion compensation, Optical Communication.

\section{Keywords}

Fiber Bragg Grating (FBG), Dispersion, Bit error rate, Dispersion compensation, Optical Communication, Nonlinear effects, Q-factor.

\section{INTRODUCTION}

Optical fibers are used for data transmission in optical fiber communication system. In optical fiber data flows in form of light. The performance of optical fiber is limited by the factor known as dispersion. Due to dispersion after a specific distance pulses get broadened which leads to errors in receiver and correct reception of bits. EDFA (erbium doped fiber amplifier) plays an important role to avoid the losses in the signal. Dispersion-shifted fibers, dispersion-flattened fibers, dispersion decreasing fibers, DCFs (dispersion compensating fiber) are used for dispersion compensation in optical communication system. DCF is the type of fiber that has the opposite dispersion (negative dispersion) of the fiber (positive dispersion) being used in a transmission system. It is used to nullify the positive dispersion of the fiber. But by using these fiber nonlinear affects [1], insertion losses [1] and cost [2] of the optical transmission system increases. Also DCF is bulky [3].

A lot of work has been reported on the importance of different pulse formats in context of dispersion compensation. It is found that for $40 \mathrm{~Gb} / \mathrm{s}$ TDM-systems, RZ-modulation format with a duty cycle of 0.5 gives better performance as compare to NRZ data format [26], [5], [6], [7], [8]. The 3rd order Gaussian pulse(RZ) gives best performance and if 3rd order Gaussian pulse is used for long distances then less timing jitter and BER is observed as compare to by using 1st and 2nd order super Gaussian pulse(RZ) [4]. If optical link is of $150 \mathrm{~km}$ then $66.9 \mathrm{ps} / \mathrm{nm} / \mathrm{km}$ dispersion is observed and dispersion of $150 \mathrm{~km}$ optical link (using FBGs as a dispersion compensator) can be compensated up to $33.8 \mathrm{ps} / \mathrm{nm} / \mathrm{km}$ [9]. If in $100 \mathrm{~km}$ standard optical link $10 \mathrm{~Gb} / \mathrm{s}$ non return to zero (NRZ) signal is transmitted then BER $=0.000875879$ is observed (without dispersion compensation) and if FBGs is used as dispersion compensator then this BER decreases from 0.000875879 to $1 \mathrm{e}-040$ [10]. It is also found that by comparing eye diagrams and $\mathrm{Q}$ parameters of dispersion compensation scheme using FBG and DCF dispersion compensation then dispersion compensation using FBG is the better method for chromatic dispersion compensation [11]. FBG is significantly different from DCF compensation. FBGs in optical communication system uses as filters [12], gain flatteners [13], highly selective filters for channel selection in dense WDM systems [14] and dispersion compensators [15]. As compare to DCF FBGs have low insertion loss, negligible nonlinearity and small size [16-17]. Fiber grating is used to compensate the chromatic dispersion (dispersion) in an optical fiber. Distortion in their phase response is the main drawback of FBGs which is known as group delay ripple (GDR) [18]. Here in this paper the work of paper [2] and Paper [19] for dispersion compensation is extended further. Paper [2] shows that performance of FBGs (dispersion compensator) on $10 \mathrm{~km}$ optical communication system and it is found that with increase in grating length the pulse extension decreases and also increase in its power [2]. In paper [2], the performance of $10 \mathrm{~km}$ optical communication was investigated but here in this paper the performance is investigated up to the length of $50 \mathrm{~km}$. From paper [19] it is concluded that optical fiber length and attenuation coefficient are directly proportional to the noise figure.

Placement of FBG, EDFA gain, length of FBG in optical system plays a very important role in performance (dispersion compensation). When FBG along with EDFA before the fiber (at the transmitter end) in the optical transmission system is used then it gives better performance (less dispersion or minimum bit error rate) as compare when FBG along with EDFA after the fiber (at the receiver end) is used in the optical transmission system. In this paper input power is varied from $-10 \mathrm{dBm}$ to $10 \mathrm{dBm}$ and performance of optical transmission system is investigated $(10 \mathrm{~km}, 20 \mathrm{~km}, 30 \mathrm{~km}, 40 \mathrm{~km}$, and $50 \mathrm{~km})$. FBG length is also varied from $(2 \mathrm{~mm}, 4 \mathrm{~mm}, 6 \mathrm{~mm}$, 
$8 \mathrm{~mm}, 10 \mathrm{~mm}, 12 \mathrm{~mm}, 14 \mathrm{~mm}$ ) for different length of optical transmission system.

This paper also includes the effect of variation of EDFA gain on the performance (minimum bit error rate) of optical transmission system. It shows that variation of EDFA gain plays a significant role in performance of transmission system. In the first section of this paper the performance (Minimum BER) of two systems (FBG along with EDFA after the fiber (at receiver end) in the optical transmission system, FBG along with EDFA before the fiber (at the transmitter end) in the optical transmission system) is investigated by plotting the graph between input power and BER. In second section performance is investigated by plotting the graph between FBG length and BER. In third section performance is investigated by plotting the graph between EDFA gain and BER.

\section{SYSTEM DESCRIPTION}

Working principle of FBG:- FBG is shown in Fig. 1.

$$
\begin{aligned}
\lambda_{1} & <\lambda_{2}<\lambda_{3}<\lambda_{4} \\
& \text { Grating spacing increases }
\end{aligned}
$$

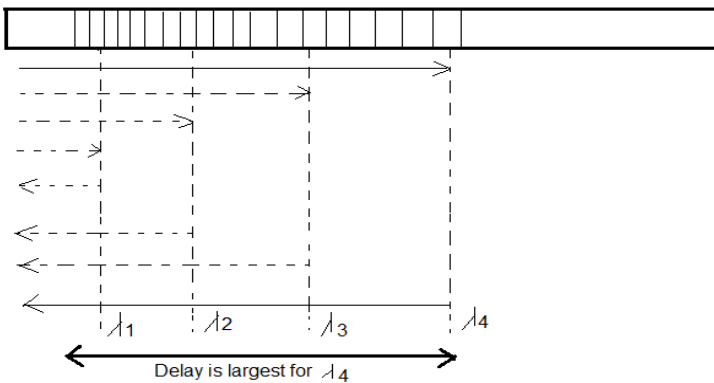

Fig 1: Working principle of FBG.

The fiber bragg grating is made so segments which reflects different wavelengths are in different positions along the length of fiber. Let the longer wavelengths $\left(\lambda_{4}\right)$ arrived first and shorter wavelengths $\left(\lambda_{1}\right)$ arrived last. The longer wavelengths are transmitted through to the last part of gratings and shorter wavelengths are reflected by the first part of grating. Due to this longer wavelength have to travel a longer distance, so they are delayed, allowing the shorter wavelength to catch up. Layout of dispersion compensation module based on fiber bragg grating is shown in Fig. 2 .

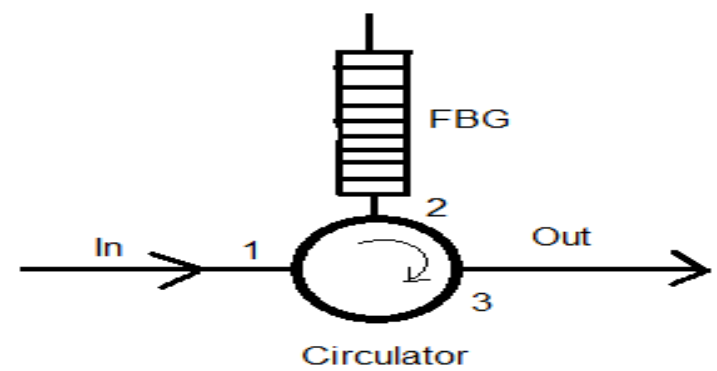

Fig 2: Dispersion compensation module based on fiber bragg grating (FBG).

The diagrams of optical transmission system (Fig. 3.,Fig. 4)are as:-

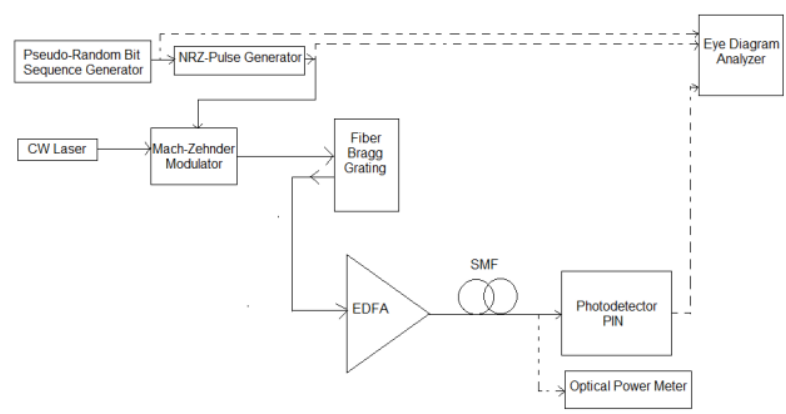

Fig 3: FBG along with EDFA before the fiber (at transmitter end) in the optical transmission system.

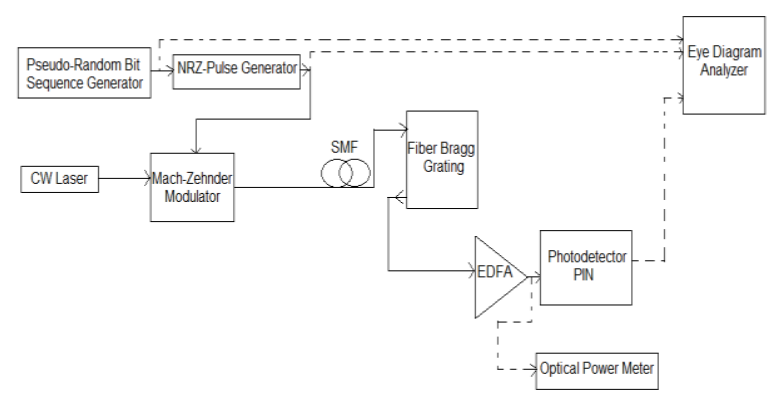

Fig 4: FBG along with EDFA after the fiber (at receiver end) in the optical transmission system.

The function of Pseudo-random bit sequence generator is to scramble data signal in terms of bit rates [20]. Here it is producing 10 Gbps bit rate. NRZ-pulse Generator produces the electrical data signal for modulation process [19]. Continuous Wave (CW) laser with frequency $193.1 \mathrm{THz}$ is applied to the system and it is modulated externally with nonreturn-zero (NRZ) pseudorandom binary sequence in a Mach -Zehnder modulator. Mach-Zehnder has extinction ratio of 30 dB. Signal flows through single mode optical fiber. FBG is used to compensate the chromatic dispersion of optical fiber which arises during the travelling of signal in fiber as the distance increases. The function of erbium-doped fiber amplifier (EDFA) is to compensate the loses in optical transmission system. Function of photodector is detection of light (photon) at the receiver. It converts light directly into current. Eye Diagram Analyzer is used for checking the minimum bit error rate. Optical power meter is used is used for checking the received signal power level.

\section{FIRST SECTION:-COMPARISON ON THE BASIS OF INPUT POWER VERSES BER}

This section describes comparison between transmitted power with BER at different values of distances $(10,20,30,40,50$ $\mathrm{Km})$. For a particular value of distance eg- $10 \mathrm{~km}$, power is varied from $-10 \mathrm{dBm}$ to $10 \mathrm{dBm}$. The length of the FBG is also varied from $2 \mathrm{~mm}$ to $14 \mathrm{~mm}$. The minimum BER obtained is plotted against transmitted power.

The system achieves a low BER for a particular power, then afterward it increases. Graph between input power and BER for dispersion compensation with FBG and EDFA at transmitter end is shown in Fig. 5. 


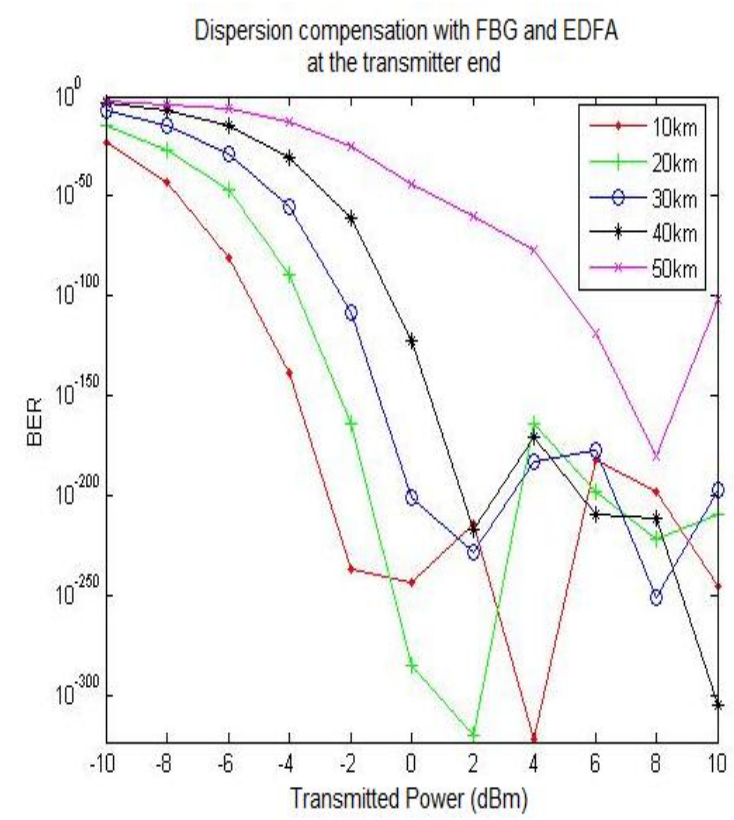

Fig 5: Graph between input power and BER for dispersion compensation with FBG and EDFA at transmitter end.

For $10 \mathrm{~km}$ minimum BER of $1.87745 \mathrm{e}-322$ is observed at $4 \mathrm{dBm}$ input power. For $20 \mathrm{~km}$ minimum BER of $1.29445 \mathrm{e}-$ 320 is observed at $2 \mathrm{dBm}$ input power. For $30 \mathrm{~km}$ minimum BER of $1.8834 \mathrm{e}-251$ is observed at $8 \mathrm{dBm}$ input power. For $40 \mathrm{~km}$ minimum BER of $2.16954 \mathrm{e}-305$ is observed at $10 \mathrm{dBm}$. For $50 \mathrm{~km}$ minimum BER of $4.16583 \mathrm{e}-181$ is observed at $8 \mathrm{dBm}$.

Graph between input power and BER for dispersion compensation with FBG and EDFA at receiver end is shown in Fig. 6.

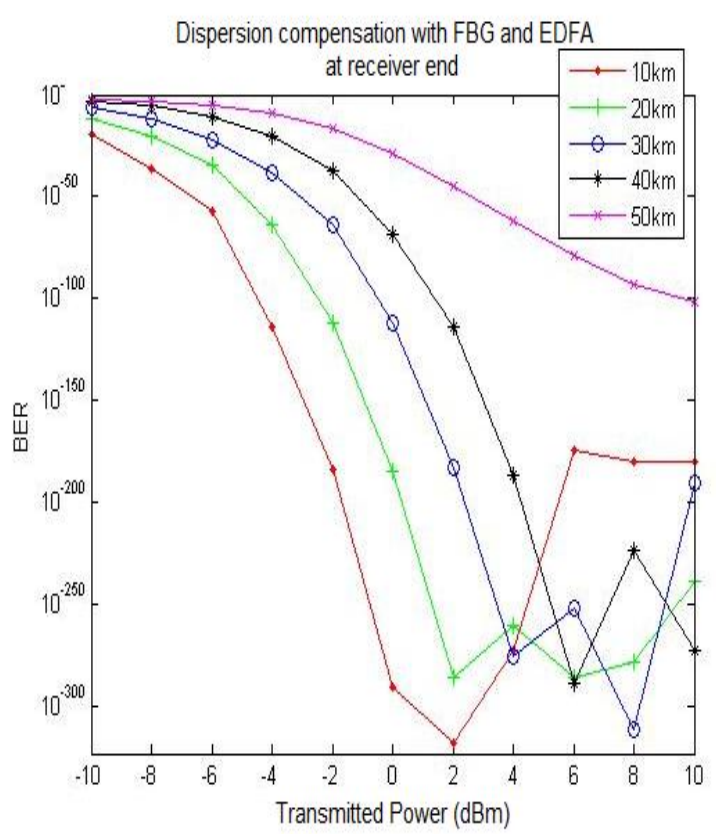

Fig 6: Graph between input power and BER for dispersion compensation with FBG and EDFA at receiver end.
For $10 \mathrm{~km}$ minimum BER of $6.73614 \mathrm{e}-319$ is observed at $2 \mathrm{dBm}$ input power. For $20 \mathrm{~km}$ minimum BER of $4.90116 \mathrm{e}-$ 287 is observed at $2 \mathrm{dBm}$ input power. For $30 \mathrm{~km}$ minimum BER of $1.39294 \mathrm{e}-312$ is observed at $8 \mathrm{dBm}$ input power. For $40 \mathrm{~km}$ minimum BER of $7.5984 \mathrm{e}-290$ is observed at $6 \mathrm{dBm}$. For $50 \mathrm{~km}$ minimum BER of $1.10874 \mathrm{e}-102$ is observed at $10 \mathrm{dBm}$.

Comparison of graphs in Fig. 5 and Fig. 6 on the basis of minimum BER for particular distance is shown in table 1.

Table 1.

\begin{tabular}{|c|c|c|c|c|}
\hline $\begin{array}{l}\text { Distan } \\
\text { ce } \\
(\mathrm{km})\end{array}$ & $\begin{array}{l}\text { Transmitte } \\
-\mathrm{d} \text { Input } \\
\text { power (d } \\
\text { Bm) level } \\
\text { for } \\
\text { Dispersion } \\
\text { compensat } \\
\text { ion with } \\
\text { FBG and } \\
\text { EDFA at } \\
\text { transmitter } \\
\text { end }\end{array}$ & $\begin{array}{l}\text { Minimum } \\
\text { BER for } \\
\text { Dispersio- } \\
\mathrm{n} \\
\text { compensat } \\
\text { ion with } \\
\text { FBG and } \\
\text { EDFA at } \\
\text { transmitter } \\
\text { end }\end{array}$ & $\begin{array}{l}\text { Transmitte } \\
\text {-d Input } \\
\text { power (d } \\
\text { Bm) level } \\
\text { for } \\
\text { Dispersion } \\
\text { compensat } \\
\text { ion with } \\
\text { FBG and } \\
\text { EDFA at } \\
\text { receiver } \\
\text { end }\end{array}$ & $\begin{array}{l}\text { Minimum } \\
\text { BER for } \\
\text { Dispersio- } \\
\mathrm{n} \\
\text { compensat } \\
\text { ion with } \\
\text { FBG and } \\
\text { EDFA at } \\
\text { receiver } \\
\text { end }\end{array}$ \\
\hline $10 \mathrm{~km}$ & $4 \mathrm{dBm}$ & $\begin{array}{l}1.87745 \mathrm{e}- \\
322\end{array}$ & $2 \mathrm{dBm}$ & $\begin{array}{l}6.73614 \mathrm{e}- \\
319\end{array}$ \\
\hline $20 \mathrm{~km}$ & $2 \mathrm{dBm}$ & $\begin{array}{l}1.29445 \mathrm{e}- \\
320\end{array}$ & $2 \mathrm{dBm}$ & $\begin{array}{l}4.90116 \mathrm{e}- \\
287\end{array}$ \\
\hline $30 \mathrm{~km}$ & $8 \mathrm{dBm}$ & $\begin{array}{l}1.8834 \mathrm{e}- \\
251\end{array}$ & $8 \mathrm{dBm}$ & $\begin{array}{l}1.39294 \mathrm{e}- \\
312\end{array}$ \\
\hline $40 \mathrm{~km}$ & $10 \mathrm{dBm}$ & $\begin{array}{l}2.16954 \mathrm{e}- \\
305\end{array}$ & $6 \mathrm{dBm}$ & $\begin{array}{l}7.5984 \mathrm{e}- \\
290\end{array}$ \\
\hline $50 \mathrm{~km}$ & $8 \mathrm{dBm}$ & $\begin{array}{l}4.16583 \mathrm{e}- \\
181\end{array}$ & $10 \mathrm{dBm}$ & $\begin{array}{l}1.10874 \mathrm{e}- \\
102\end{array}$ \\
\hline
\end{tabular}

After comparisons of the BER values for the two configurations, it can be concluded that the optical system using FBG and EDFA at the transmitter end has a better performance except for $30 \mathrm{~km}$. Thus the placement of FBG and EDFA in optical transmission system plays an important role to reduce the BER of optical system.

Comparison of eye diagram for $10,20,30,40,50 \mathrm{~km}$ using dispersion compensation with FBG and EDFA at transmitter end and using dispersion compensation with FBG and EDFA at receiver end is shown in Fig 7.1, 7.2, 7.3, 7.4, 7.5, 7.6, 7.7, 7.8, 7.9, 7.10. 


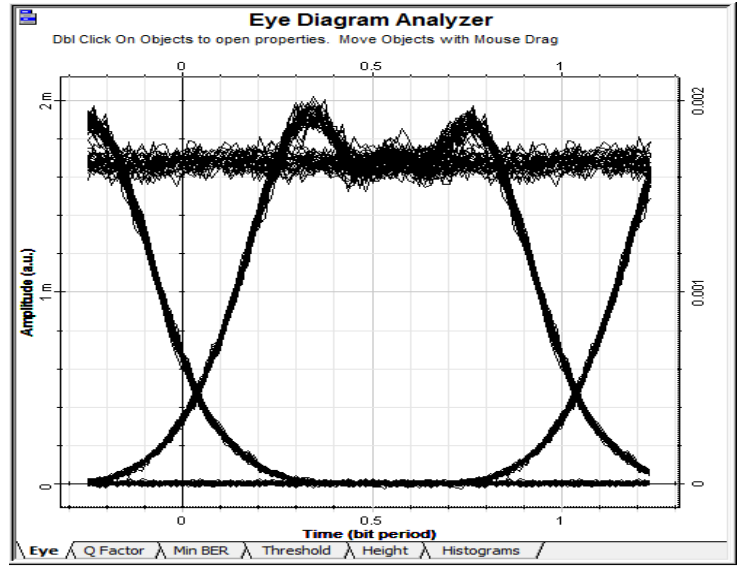

Fig 7.1: Eye diagram for the system using dispersion compensation at transmitter end system for $10 \mathrm{Km}$.

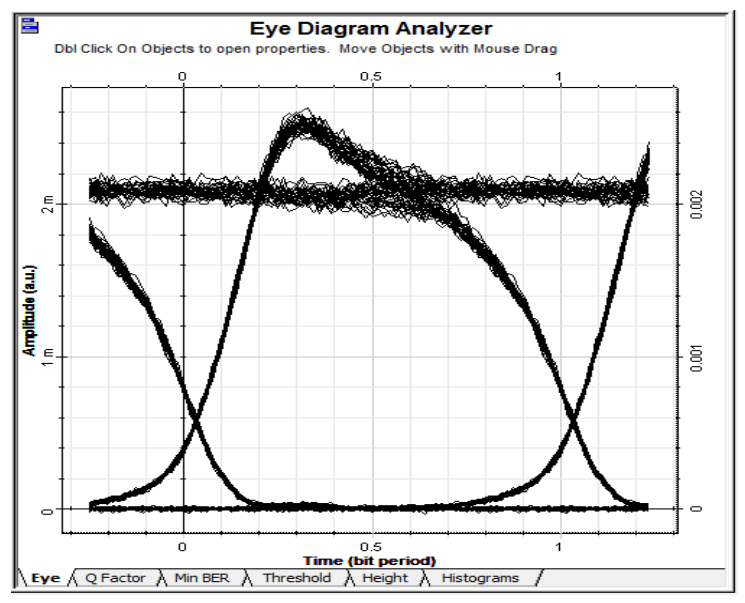

Fig 7.3: Eye diagram for the system using dispersion compensation at transmitter end system for $20 \mathrm{~km}$.

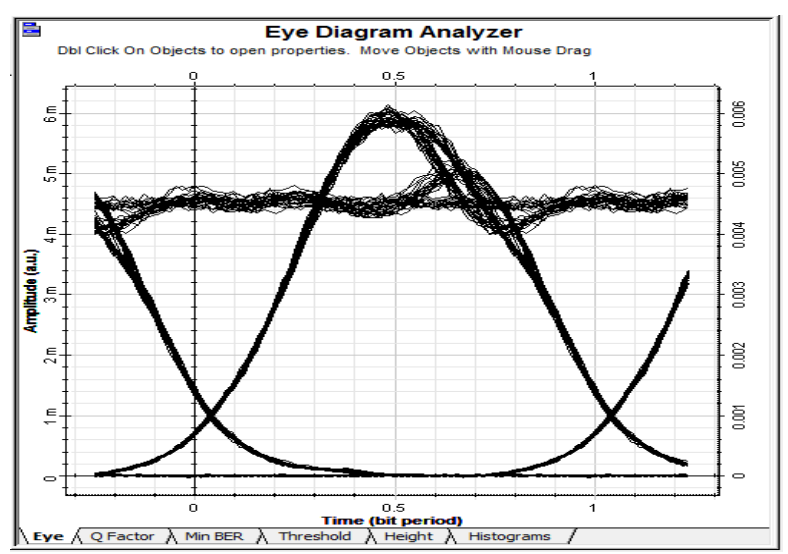

Fig 7.5: Eye diagram for the system using dispersion compensation at transmitter end system for $30 \mathrm{~km}$.

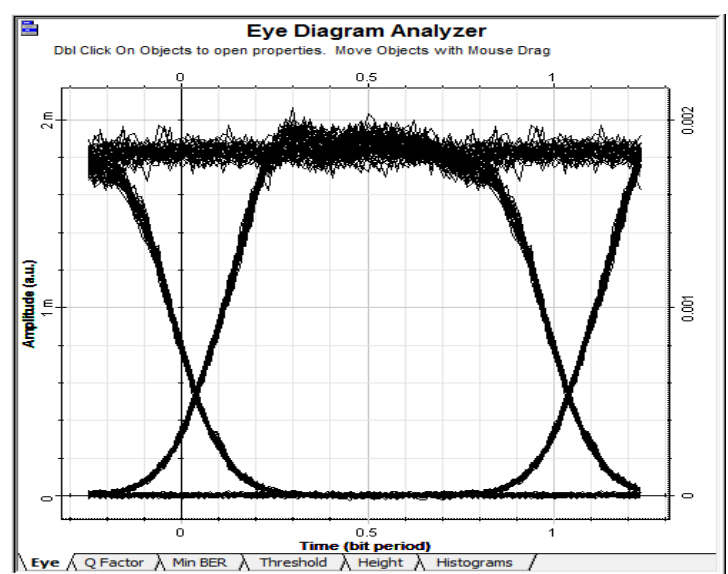

Fig 7.2: Eye diagram for the system using dispersion compensation at receiver end system for $10 \mathrm{~km}$.

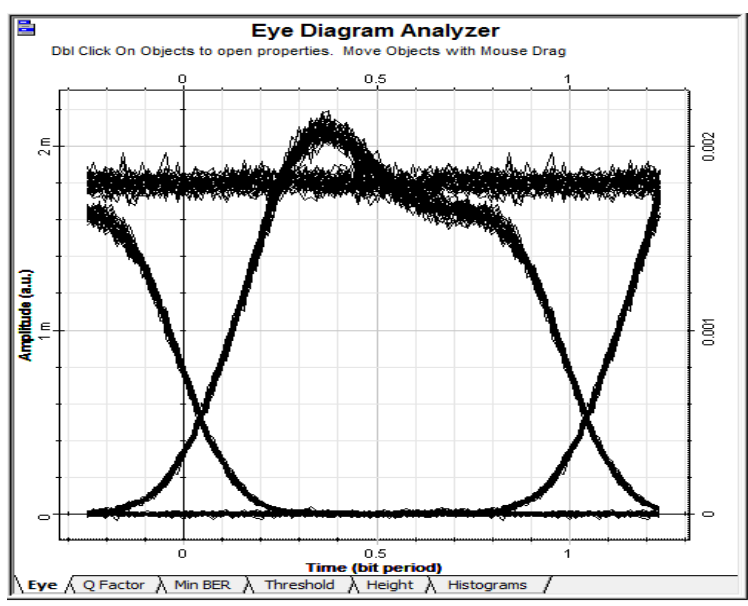

Fig 7.4: Eye diagram for the system using dispersion compensation at receiver end system for $20 \mathrm{~km}$.

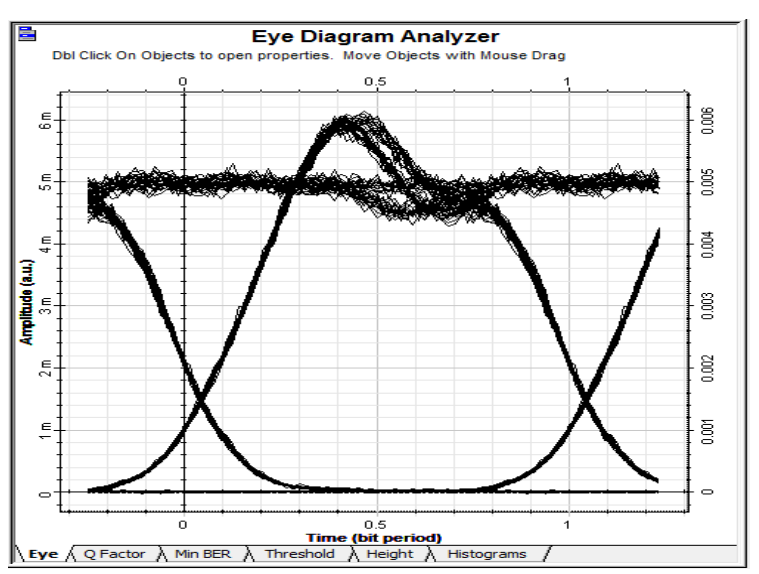

Fig 7.6: Eye diagram for the system using dispersion compensation at receiver end system for $30 \mathrm{~km}$. 


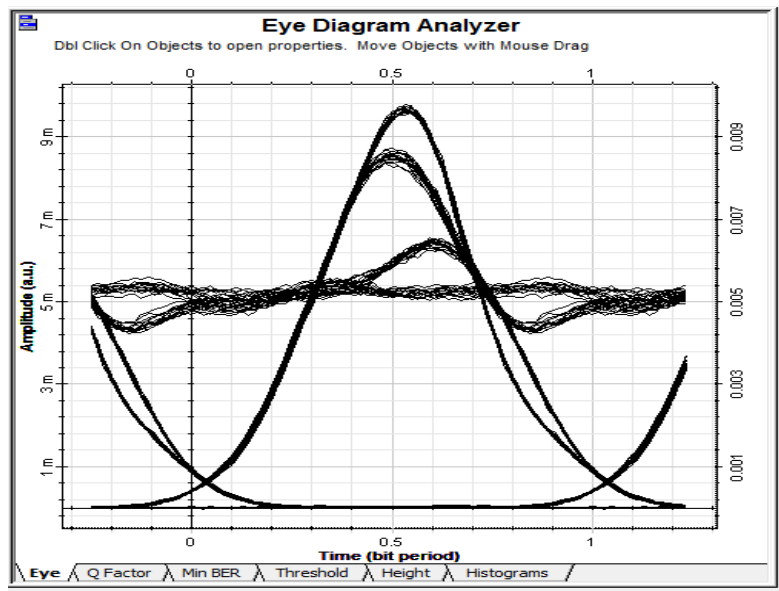

Fig 7.7: Eye diagram for the system using dispersion compensation at transmitter end system for $\mathbf{4 0} \mathbf{~ k m}$.

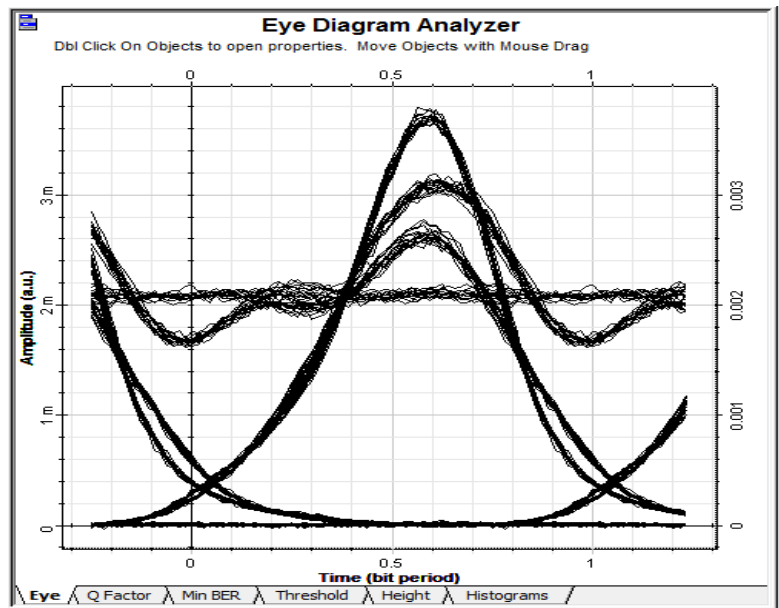

Fig 7.9: Eye diagram for the system using dispersion compensation at transmitter end system for $50 \mathrm{~km}$.
Comparison of Q-factor in Dispersion compensation with FBG and EDFA at transmitter end and at receiver end is shown in Table 2.

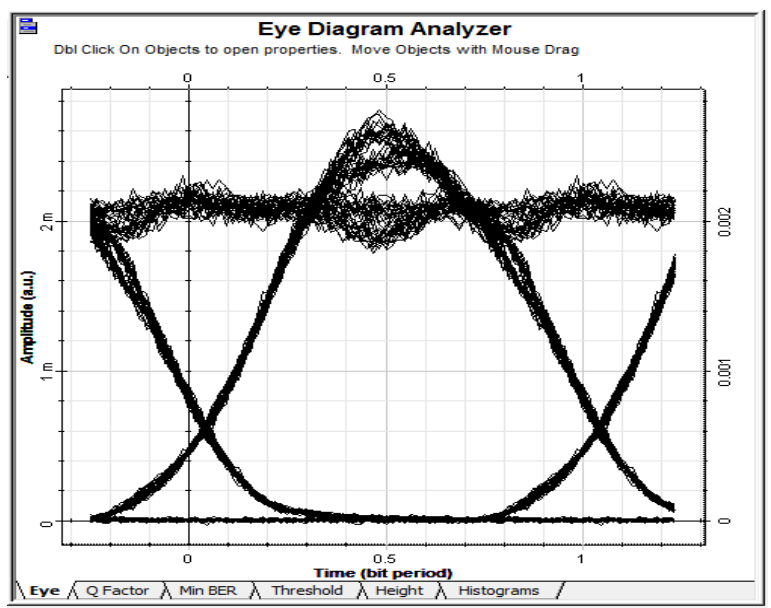

Fig 7.8: Eye diagram for the system using dispersion compensation at receiver end system for $40 \mathrm{~km}$.

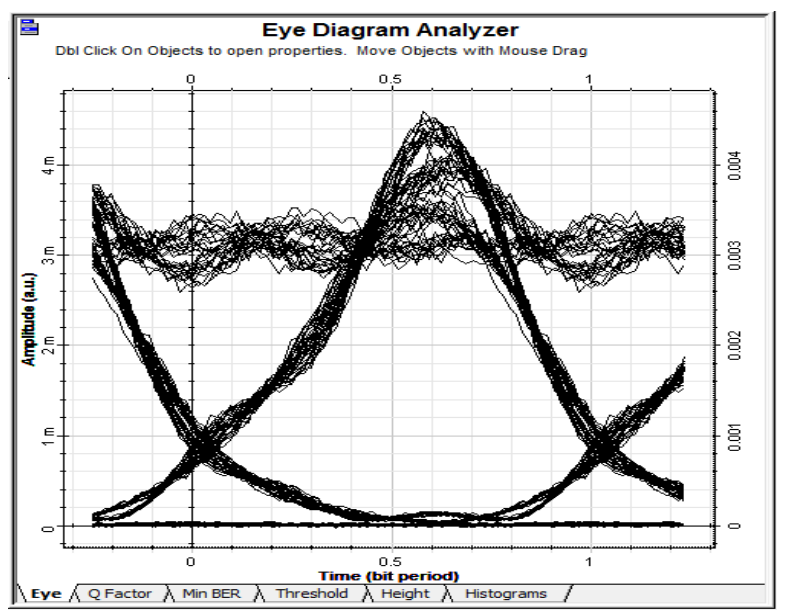

Fig 7.10: Eye diagram for the system using dispersion compensation at receiver end system for $50 \mathrm{~km}$. 
Table 2. Comparison of Q-factor when Dispersion compensation with FBG and EDFA at transmitter end and at receiver end

\begin{tabular}{|c|c|c|}
\hline Distance $(\mathrm{km})$ & $\begin{array}{c}|c| \\
\text { Q-factor } \\
\text { compensation with } \\
\text { FBG and EDFA at } \\
\text { transmitter end }\end{array}$ & $\begin{array}{l}\text { Q-factor } \\
\text { when Dispersion } \\
\text { compensation with } \\
\text { FBG and EDFA at } \\
\text { receiver end }\end{array}$ \\
\hline $10 \mathrm{~km}$ & 38.3669 & 38.1523 \\
\hline $20 \mathrm{~km}$ & 38.259 & 36.1797 \\
\hline $30 \mathrm{~km}$ & 33.8485 & 37.7741 \\
\hline $40 \mathrm{~km}$ & 37.3261 & 36.3565 \\
\hline $50 \mathrm{~km}$ & 28.6676 & 21.4802 \\
\hline
\end{tabular}

Except for $30 \mathrm{~km}$ case, the Q factor observed for both the configurations at distances of $10,20,40,50 \mathrm{Km}$ reveals that the system employing FBG and EDFA at the transmitter gives a better performance.

It is observed that the BER in the system first falls down to a minimum and then it increases after reaching a particular input power level.

The BER initially falls down because at low power level when EDFA amplifies the incoming signal at receiver (by stimulated emission) there are more number of erbium ion available for amplification and EDFA generate less noise (by spontaneous emission). More availability of erbium ion provides better amplification of signal and therefore BER decreases [21] (falls down initially).

The BER with the optimum setting of decision threshold (for choosing whether bit is a 1 or 0 ) is given by [1]:-

$$
B E R=\frac{1}{2} \operatorname{erfc}\left(\frac{Q}{\sqrt{2}}\right) \approx \frac{\exp \left(\frac{-Q^{2}}{2}\right)}{Q \sqrt{2 \pi}}
$$

Where Q-factor is given by $Q=\frac{I_{1}-I_{0}}{\sigma_{1}+\sigma_{0}}$

$I_{0}$ and $I_{1}$ are the average photocurrent generated by a 0 bit and 1 bit respectively.

$\sigma_{0}^{2}$ and $\sigma_{1}^{2}$ are the noise variances for 0 bit and 1 bit respectively.

BER and $\mathrm{Q}$ are directly proportional to each other. BER improves as $\mathrm{Q}$ increases. Also $\mathrm{Q}$ is directly proportional to average received power $\left(\overline{P_{r e c}}\right)[1]$.

BER is also given by [1]-

$$
B E R=\operatorname{erfc}\left(\sqrt{\eta N_{P} / 2}\right)
$$

Where $\eta N_{P}=\mathrm{Q}, N_{P}$ is the average number of photon contained within the " 1 " bit.
The main reason of increase in BER of optical fiber communication system is nonlinear effects in fiber. Nonlinear effects are Raman scattering (SRS), stimulated Brillouin scattering (SBS) and kerr effect [22]. Kerr effect include selfphase modulation (SPM), cross-phase modulation (XPM), and four-wave mixing (FWM). Kerr effect arises from intensitydependent variations in the refractive index in the silica fiber [22]. EDFA adds noise caused by amplified spontaneous emission (ASE) that propagates along with the signal and increase BER (broadens the pulse) when signal is received. EDFA amplifies the incoming signal (by stimulated emission) but spontaneous emission also takes place there. This emission adds noise in the signal. At low power ASE level is less. Combination of nonlinear effects and EDFA's ASE noise increase the BER at the receiver.

Further the spectrum of bit stream is observed and it is found that the spectrum broadens as the input power is increased in the fiber. This broadening is due to the combined effect of non -linear effects and ASE. Due to this broadening, there are side lobes at different neighbouring wavelengths. Such side lobes reduce the power in central wavelength and are responsible for increase in BER. Due to these reasons BER after reaching a particular power level starts increasing.

Spectrum of input bit stream observed at the output of EDFA for different input power levels are shown in Fig. 8.1, 8.2, 8.3, $8.4,8.5-$

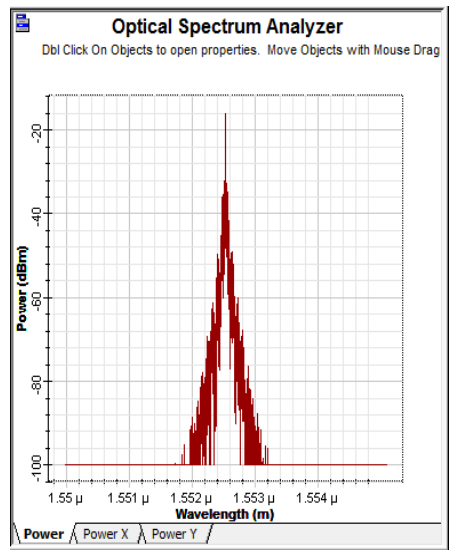

Fig 8.1: Spectrum of input bit stream when input power is $-10 \mathrm{dBm}$.

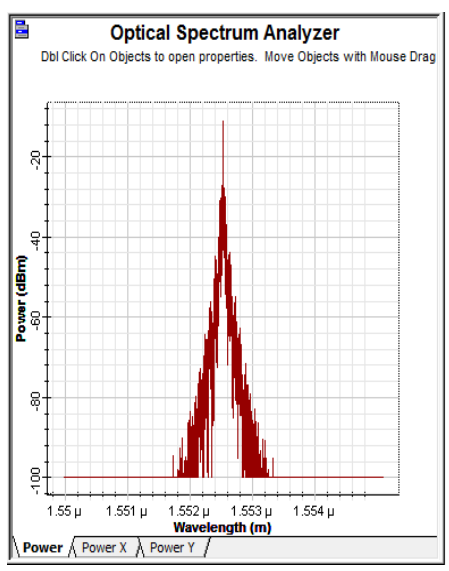


Fig 8.2: Spectrum of input bit stream when input power is $-5 \mathrm{dBm}$.

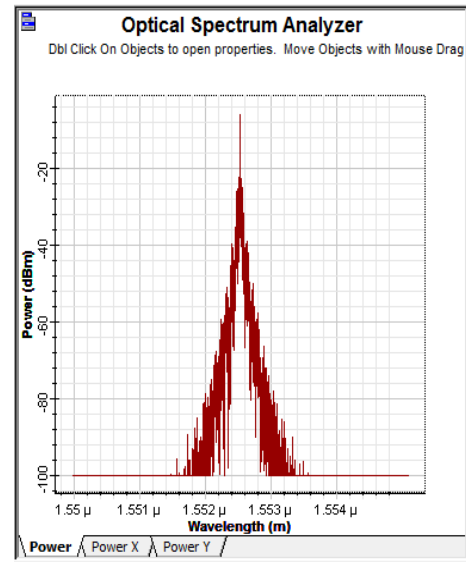

Fig 8.3: Spectrum of input bit stream when input power is $0 \mathrm{dBm}$.

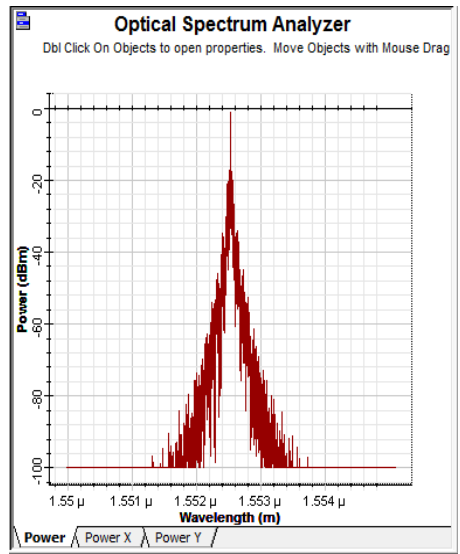

Fig 8.4: Spectrum of input bit stream when input power is $5 \mathrm{dBm}$.

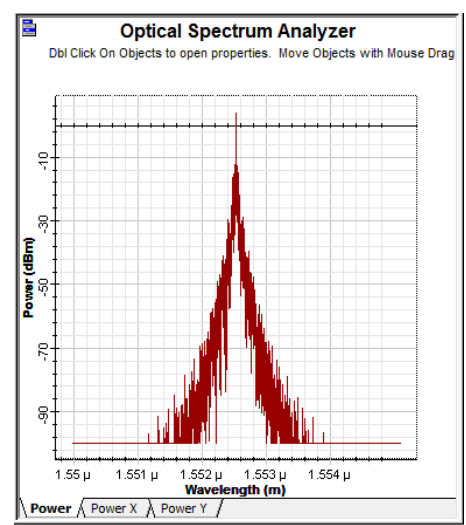

Fig 8.5: Spectrum of input bit stream when input power is $10 \mathrm{dBm}$.
These results shows that with for low input power initially BER curve goes down and when power increases then BER curve start to increase.

\section{SECOND SECTION :- COMPARISON ON THE BASIS OF FBG LENGTH AND BER:-}

This section describes the comparison between FBG length with BER at different values of distances $(10,20,30,40,50$ $\mathrm{km})$. Input power to the optical system is varied between -10 to $10 \mathrm{dBm}$; BER is observed using BER analyser. The resulting minimum BER (out of that available at different input power level) is plotted against FBG length.

From the graph in Fig. 9 and Fig. 10 it can seen that FBG length plays an important role in decreasing the BER. The system achieves a low BER for a particular FBG length, and then afterward it increases.

Graph between FBG length and BER for dispersion compensation with FBG and EDFA at transmitter end is shown in Fig. 9.

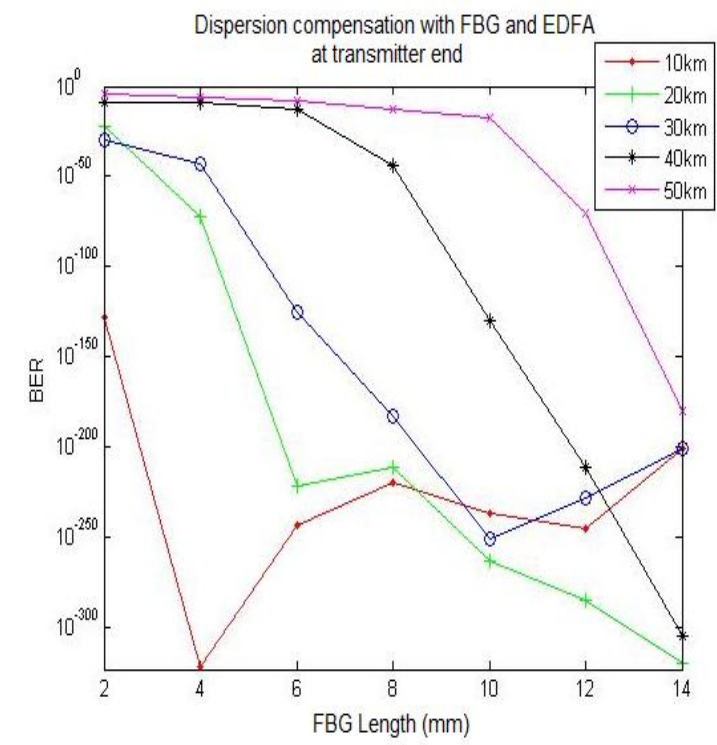

Fig 9: Graph between FBG length and BER for dispersion compensation with FBG and EDFA at transmitter end.

Graph between FBG length and BER for dispersion compensation with FBG and EDFA at receiver end is shown in Fig. 10. 


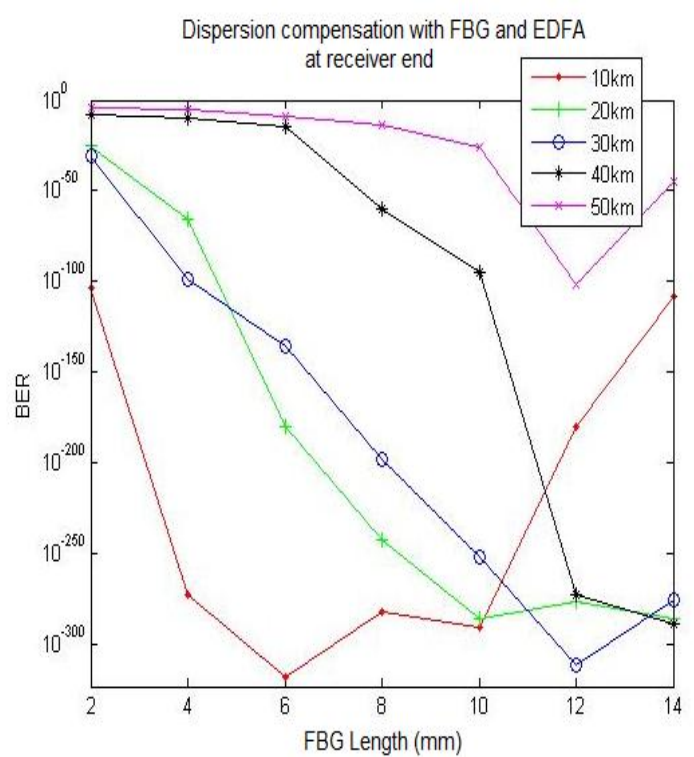

Fig 10: Graph between FBG length and BER for dispersion compensation with FBG and EDFA at receiver end.

Comparison of graphs in Fig. 9, Fig. 10 on the basis of minimum BER for particular distance is shown in Table 3.

Table 3. Comparison on the basis of minimum BER for particular distance.

\begin{tabular}{|c|c|c|c|c|}
\hline $\begin{array}{l}\text { Distan } \\
\text { ce } \\
(\mathrm{km})\end{array}$ & $\begin{array}{l}\text { FBG } \\
\text { Length } \\
(\mathrm{mm}) \text { for } \\
\text { Dispersion } \\
\text { compensat } \\
\text { ion with } \\
\text { FBG and } \\
\text { EDFA at } \\
\text { transmitter } \\
\text { end }\end{array}$ & $\begin{array}{l}\text { Minimum } \\
\text { BER for } \\
\text { Dispersion } \\
\text { compensat } \\
\text { ion with } \\
\text { FBG and } \\
\text { EDFA at } \\
\text { transmitter } \\
\text { end }\end{array}$ & $\begin{array}{l}\text { FBG } \\
\text { Length } \\
(\mathrm{mm}) \text { for } \\
\text { Dispersion } \\
\text { compensat } \\
\text { ion with } \\
\text { FBG and } \\
\text { EDFA at } \\
\text { receiver } \\
\text { end }\end{array}$ & $\begin{array}{l}\text { Minimum } \\
\text { BER for } \\
\text { Dispersion } \\
\text { compensat } \\
\text { ion with } \\
\text { FBG and } \\
\text { EDFA at } \\
\text { receiver } \\
\text { end }\end{array}$ \\
\hline $10 \mathrm{~km}$ & $4 \mathrm{~mm}$ & $\begin{array}{l}1.87745 \mathrm{e}- \\
322\end{array}$ & $6 \mathrm{~mm}$ & $\begin{array}{l}6.73614 \mathrm{e}- \\
319\end{array}$ \\
\hline $20 \mathrm{~km}$ & $14 \mathrm{~mm}$ & $\begin{array}{l}1.29445 \mathrm{e}- \\
320\end{array}$ & $10 \mathrm{~mm}$ & $\begin{array}{l}4.90116 \mathrm{e}- \\
287\end{array}$ \\
\hline $30 \mathrm{~km}$ & $10 \mathrm{~mm}$ & $\begin{array}{l}1.8834 \mathrm{e}- \\
251\end{array}$ & $12 \mathrm{~mm}$ & $\begin{array}{l}1.39294 \mathrm{e}- \\
312\end{array}$ \\
\hline $40 \mathrm{~km}$ & $14 \mathrm{~mm}$ & $\begin{array}{l}2.16954 \mathrm{e}- \\
305\end{array}$ & $14 \mathrm{~mm}$ & $\begin{array}{l}7.5984 \mathrm{e}- \\
290\end{array}$ \\
\hline $50 \mathrm{~km}$ & $14 \mathrm{~mm}$ & $\begin{array}{l}4.16583 \mathrm{e}- \\
181\end{array}$ & $12 \mathrm{~mm}$ & $\begin{array}{l}4.40182 \mathrm{e}- \\
046\end{array}$ \\
\hline
\end{tabular}

From the table, it is clear that except for $30 \mathrm{~km}$ the optical system using FBG and EDFA at the transmitter end achieves less BER as compare to optical system using FBG and EDFA at the receiver end. Thus the placement of FBG and EDFA along with proper selection of FBG length in optical transmission system plays an important role to reduce the BER of optical system.
Initially, the BER decreases with increase in the length of FBG. The reason behind the decrease is that if the grating length increases, the group delay of reflection band increases (power reflectivity increases) and therefore dispersion compensated bandwidth increases [23]. So the margin of the distance increases over which the compensation is taking place.

After an optimum length the BER starts to increase. The reason behind the increase in BER is due to the increase in sidelobe level in the reflectivity spectrum [24]. The sidelobes increase the insertion losses and thus lead to increase in BER [25].

\section{THIRD SECTION :- COMPARISON ON THE BASIS OF EDFA GAIN VERSES BER:-}

This section describes comparison between EDFA gain (dB) with BER at different values of distances $(10,20,30,40,50$ $\mathrm{Km})$. The launched power is kept $-10 \mathrm{dBm}$ for all values of distance. EDFA gain is varied and the BER is observed, while the minimum BER obtained for different FBG lengths is plotted against EDFA gain.

Graph shows that increase in EDFA gain plays a very important role in decreasing the BER. The system achieves a low BER for a particular EDFA gain. With increase in EDFA gain, BER decreases. Graph between EDFA gain and BER for dispersion compensation with FBG and EDFA at transmitter end is shown in Fig. 11.

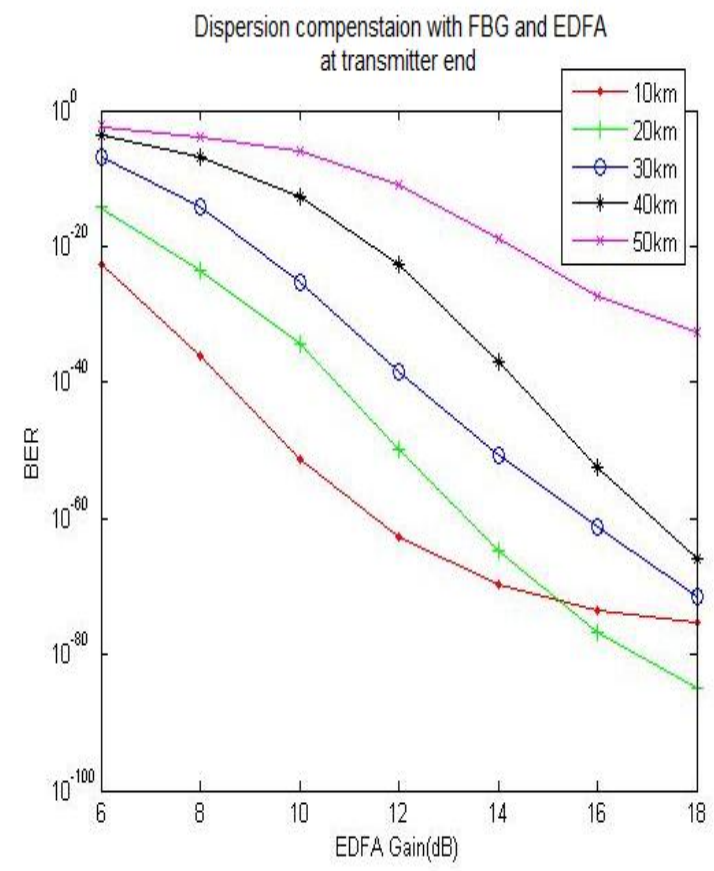

Fig 11: Graph between EDFA gain and BER for dispersion compensation with FBG and EDFA at transmitter end.

From the graph in Fig. 11 it is obseved that with increase in EDFA gain (for transmitter side) BER keeps on decreasing.

Graph between EDFA gain and BER for dispersion compensation with FBG and EDFA at receiver end is shown in Fig.12. 


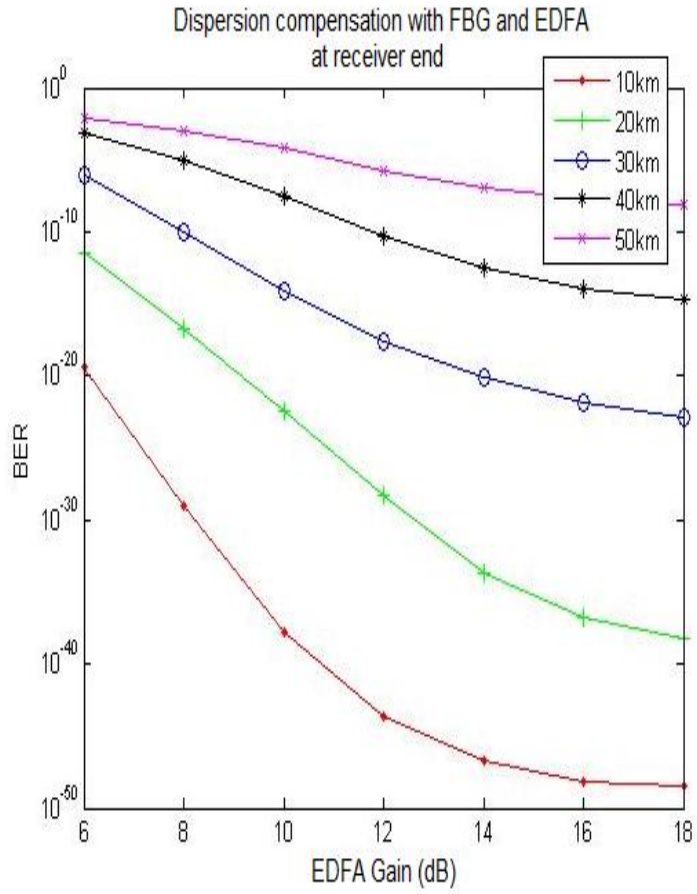

Fig 12: Graph between EDFA gain and BER for dispersion compensation with FBG and EDFA at receiver end.

From the graph in Fig. 12 the lowest value of BER is obtained at an EDFA gain of $16 \mathrm{~dB}$. But after that $(16 \mathrm{~dB})$ it starts to saturate. So, $16 \mathrm{~dB}$ is the optimum value of gain for dispersion compensation with FBG and EDFA at receiver end.

Comparison of graph in Fig. 11, Fig. 12 on the bases of minimum BER for a particular distance is shown in table 4 .

Table 4. Comparison of graph on the bases of minimum BER for a particular distance

\begin{tabular}{|c|c|c|c|c|}
\hline $\begin{array}{l}\text { Distan } \\
\text { ce } \\
(\mathrm{km})\end{array}$ & $\begin{array}{l}\text { EDFA } \\
\text { gain }(\mathrm{dB}) \\
\text { for } \\
\text { Dispersion } \\
\text { compensat } \\
\text { ion with } \\
\text { FBG and } \\
\text { EDFA at } \\
\text { transmitter } \\
\text { end }\end{array}$ & $\begin{array}{l}\text { Minimum } \\
\text { BER for } \\
\text { Dispersion } \\
\text { compensat } \\
\text { ion with } \\
\text { FBG and } \\
\text { EDFA at } \\
\text { transmitter } \\
\text { end }\end{array}$ & $\begin{array}{l}\text { EDFA } \\
\text { gain }(\mathrm{dB}) \\
\text { for } \\
\text { Dispersion } \\
\text { compensat } \\
\text { ion with } \\
\text { FBG and } \\
\text { EDFA at } \\
\text { receiver } \\
\text { end }\end{array}$ & $\begin{array}{l}\text { Minimum } \\
\text { BER for } \\
\text { Dispersion } \\
\text { compensat } \\
\text { ion with } \\
\text { FBG and } \\
\text { EDFA at } \\
\text { receiver } \\
\text { end }\end{array}$ \\
\hline $10 \mathrm{~km}$ & $18 \mathrm{~dB}$ & $\begin{array}{l}3.99917 \mathrm{e}- \\
076\end{array}$ & $16 \mathrm{~dB}$ & $\begin{array}{l}7.23851 \mathrm{e}- \\
049\end{array}$ \\
\hline $20 \mathrm{~km}$ & $18 \mathrm{~dB}$ & $\begin{array}{l}9.23505 \mathrm{e}- \\
086\end{array}$ & $16 \mathrm{~dB}$ & $\begin{array}{l}1.64977 \mathrm{e}- \\
037\end{array}$ \\
\hline $30 \mathrm{~km}$ & $18 \mathrm{~dB}$ & $\begin{array}{l}4.01022 \mathrm{e}- \\
072\end{array}$ & $16 \mathrm{~dB}$ & $\begin{array}{l}1.39974 \mathrm{e}- \\
022\end{array}$ \\
\hline $40 \mathrm{~km}$ & $18 \mathrm{~dB}$ & $\begin{array}{l}1.24679 \mathrm{e}- \\
066\end{array}$ & $16 \mathrm{~dB}$ & $\begin{array}{l}1.19253 \mathrm{e}- \\
014\end{array}$ \\
\hline $50 \mathrm{~km}$ & $18 \mathrm{~dB}$ & $\begin{array}{l}1.98315 \mathrm{e}- \\
033\end{array}$ & $16 \mathrm{~dB}$ & $\begin{array}{l}1.87345 \mathrm{e}- \\
008\end{array}$ \\
\hline
\end{tabular}

Therefore, except for $30 \mathrm{~km}$ the optical system using FBG and EDFA at the transmitter end has a less BER as compare to optical system using FBG and EDFA at the receiver end. Thus the placement of FBG and EDFA in optical transmission system plays an important role to reduce the BER of optical system.

From paper [2] for $10 \mathrm{~km}$ optical communication system (using input power $1 \mathrm{~mW}$, FBG length $6 \mathrm{~mm}$ ) minimum BER observed is 1.35988e-198 (according to their parameter setting) but our results (using FBG and EDFA at transmitter side) reduces this minimum BER from $1.35988 \mathrm{e}-198$ to $2.41949 \mathrm{e}-244$ with better signal waveform (reception) at eye diagram analyser. In paper [4], pre compensation (dispersion compensation at transmitter side) scheme gives BER< $10^{-10}$ for $120 \mathrm{~km}$ optical link, but our results (dispersion compensation at transmitter side) give better performance upto $50 \mathrm{~km}$ with min BER 4.16583e-181. Also in paper [4] post compensation scheme (dispersion compensation scheme at receiver side) gives $\mathrm{BER}<10^{-20}$ for $120 \mathrm{~km}$ optical link, but our results (dispersion compensation at receiver side) give better performance upto $50 \mathrm{~km}$ with min BER 1.10874e-102.

\section{CONCLUSION}

The positioning of the FBG along with EDFA plays an important role in improvement of the optical systems performance. Results obtained give better performance (less BER) as compare to paper [2] and [4]. When FBG is used at transmitter side for dispersion compensation, it gives better performance (minimum BER) as compare to when used for compensation at receiver side. For $10 \mathrm{~km}$ BER reduces from $6.73164 \mathrm{e}-319$ to $1.87745 \mathrm{e}-322$ with input power $4 \mathrm{~dB}$, for $20 \mathrm{~km}$ BER reduces from $4.90116 \mathrm{e}-287$ to $1.29445 \mathrm{e}-320$ with input power $2 \mathrm{~dB}$, for $40 \mathrm{~km}$ BER reduces from $7.5984 \mathrm{e}-290$ to $2.16954 \mathrm{e}-305$ with input power $10 \mathrm{~dB}$, for $50 \mathrm{~km}$ bit error reduces from $1.10874 \mathrm{e}-102$ to $4.16583 \mathrm{e}-181$. Only for $30 \mathrm{~km}$ BER increases from $1.39294 \mathrm{e}-312$ to $1.8834 \mathrm{e}-251$. For 10,20 , $30,40,50 \mathrm{~km}$ to get minimum BER best FBGs length are $4 \mathrm{~mm}, 14 \mathrm{~mm}, 10 \mathrm{~mm}, 14 \mathrm{~mm}, 14 \mathrm{~mm}$ respectively. The gain of the EDFA also plays an important role in systems performance. For configuration (FBG at the transmitter end), $18 \mathrm{~dB}$ gain has given the best results and for configuration (FBG at the receiver) $16 \mathrm{~dB}$ gain has given the best results.

\section{REFRENCES}

[1] G.P. Agrawal , "Fiber-Optic Communication Systems", Third edition Wiley-India edition, 2002.

[2] S. O. Mohammadi, Saeed Mozaffari and M. Mahdi Shahidi, "Simulation of a transmission system to compensate dispersion in an optical fiber by chirp gratings", International Journal of the Physical Sciences Vol. 6, No. 32, pp. 7354-7360, 2 December, 2011.

[3] D. van den Borne, V. Veljanovski, E.Gottwald, G. D. Khoe1 and H. de Waardt, "Fiber Bragg Gratings for InLine Dispersion Compensation in Cost-effective 10.7Gbit/s Long-Haul Transmission", Processing Symposium IEEE/LEOS Benelux Chapter, Eindhoven, 2006.

[4] Manjit Singh, AjayK.Sharma, R.S.Kaler, "Investigations on order and width of RZ super Gaussian pulse in pre-, post- and symmetrical-dispersion compensated $10 \mathrm{~Gb} / \mathrm{s}$ 
optical communication system using standard and dispersion compensating fibers", Optik 121, Vol. 121, Issue 7, pp. 609-616, April 2010.

[5] R.M.Mu, T. Yu, V.S. Grigoryan, C.R.Menyuk, "Dynamics of the chirped return-to-zero modulation Format", Journal of Lightwave Technology, Vol. 20, No.1, pp. 47-57, 2002.

[6] Hideki Maeda, Makoto Murakami, Norio Ohkawa, Takamasa Imai, "Optimization of signal pulse duty Factor in long-distance optical amplifier systems", IEEE Photonics Technology Letters, Vol. 10, No. 8, pp.11831185, 1998.

[7] D. Breuer, K. Ennser, K. Petermann, "Comparison of NRZ- and RZ-modulation format for $40 \mathrm{Gbit} / \mathrm{s}$ TDM Standard fibre systems", 22nd European Conference on Optical Communication, ECOC'96, Oslo, TuD.3.3, 2, pp. 199-202.

[8] E. Poutrina, G.P. Agrawal, "Effect of distributed Raman amplification on timing jitter in dispersion-managed lightwave systems", IEEE Photonics Technology Letters, Vol. 14, Issue 1, pp. 39-40, 2002.

[9] Md. Jahidul Islam, Md. Saiful Islam, Md. Mahmudur Rahman, "Dispersion Compensation in Optical Fiber Communication Using Fiber Bragg Grating", Global Journal Of Researches In Engineering Electrical And Electronics Engineering, Vol. 12, Issue 2, Version 1.0 February 2012

[10] Smita S. Dabhade \& Savita Bhosale "Fiber Bragg Grating And Phase Conjugator As Dispersion Compensator", International Journal on Advanced Electrical and Electronics Engineering, (IJAEEE), Vol. 1, Issue 1, pp. 15-19, 2012.

[11] Ladislav Stepanek, "Chromatic Dispersion In Optical Communications", Vol. VII, No. 2, pp. 142-151, July 2012.

[12] G. Meltz, W. W. Morey, and W. H. Glenn, "Formations of Bragg gratings in optical fiber by a transverse holographic method",Opt. Lett., Vol.14, No. 15, pp. 823825,1989

[13] A. M. Vengsarkar, J. R. Pedrazzani, J. B. Judkins, and P. J. Lemaire, "Long-period fiber-grating-based equilizers", Opt. Lett., Vol. 21, Issue 5, pp. 336-368, 1996.

[14] Kersey A.D., Davis M.A., Patrick H.J., Leblanc M., Koo K.P., Askins C.G., Putnam M.A. and Friebele E.J., "Fiber grating sensors", Journal of Lightwave Technology, Vol. 15, No. 8, pp. 1442-1463, 1978.
[15] F. Ouellette, "Dispersion cancellation using linearly chirped Bragg grating filters in optical waveguides", Opt. Lett., Vol. 12, No. 10, pp. 847-849, 1987.

[16] K.O. Hill and G. Meltz, "Fiber Bragg Grating technology fundamentals and overview", J. Lightwave Technol., Vol.15, No. 8, pp. 1263-1276, 1997.

[17] H. S. Fews, et. al, "Experimental Comparison of Fibre And Grating-Based Dispersion Compensation Schemes for 40 channel 10Gb/s DWDM systems", paper Th3.2.5, ECOC 2006.,

[18] C. Scheerer, et al., "Influence of Filter Group Delay Ripples on System Performance", pp. I- 410, ECOC 1999.

[19] M.A. Othman, M.M. Ismail, H.A. Sulaiman, M.H. Misran, M.A. Meor Said, Y.A. Rahim, A.N. Che Pee, M.R. Motsidi, "An Analysis of 10 Gbits/s Optical Transmission System using Fiber Bragg Grating (FBG)", IOSR Journal of Engineering (IOSRJEN), Vol. 2, No. 7, pp. 55-61, July 2012.

[20] MohamadHasrulAriffin Bin MohdBadri, "A Cost Effective Broadband ASE Light Source Based FTTH", thesis, page 20-26.

[21] Ahmed A. Elkomy, Moustafa H. Aly, W. P. Ng, Z. Ghassemlooy, and A. Abd El Aziz, "Performance of Digital Optical Communication Link : Effect of In-Line EDFA Parameters". 2010.

[22] Gred Keiser, "Optical fiber Communications", Fourth Edition McGraw-Hill, 2008.

[23] Isa Navruz , Ahmet Altuncu, "Design Of A Chirped Fiber Bragg Grating For Use In Wideband Dispersion Compensation", 2005.

[24] Abdallah Ikhlef, Rachida Hedara, Mohamed Chikh-Bled, "Uniform Fiber Bragg Grating modelling and simulation used matrix transfer method", International Journal of Computer Science Issues (IJCSI), Vol. 9, No. 2, pp. 368374, January 2012.

[25] Jaikaran Singh, Dr. Anubhuti Khare, Dr. Sudhir Kumar, "Design of Gaussian Apodized Fiber Bragg Grating and its applications", International Journal of Engineering Science and Technology, Vol. 2, No. 5, pp. 1419-1424, 2010.

[26] R.S. Kaler, Ajay K. Sharma, T.S. Kamal, "Comparison of pre-, post- and symmetrical-dispersion compensation schemes for $10 \mathrm{~Gb} / \mathrm{s}$ NRZ links using standard and dispersion compensated fibers," Optics Communications, Vol. 209, Issues 1-3, pp. 107-123, 2002. 